\title{
Disabled-1 Binds to the Cytoplasmic Domain of Amyloid Precursor-Like Protein 1
}

\author{
Ramin Homayouni, Dennis S. Rice, Michael Sheldon, and Tom Curran \\ Department of Developmental Neurobiology, St. Jude Children's Research Hospital, Memphis, Tennessee 38105
}

Disruption of the disabled-1 gene (Dab1) results in aberrant migration of neurons during development and disorganization of laminar structures throughout the brain. Dab1 is thought to function as an adapter molecule in signal transduction processes. It contains a protein-interaction (PI) domain similar to the phosphotyrosine-binding domain of the Shc oncoprotein, it is phosphorylated by the Src protein tyrosine kinase, and it binds to $\mathrm{SH} 2$ domains in a phosphotyrosine-dependent manner. To investigate the function of Dab1, we searched for binding proteins using the yeast two-hybrid system. We found that the PI domain of Dab1 interacts with the amyloid precursor-like protein 1 (APLP1). The association of Dab1 with APLP1 was confirmed in biochemical assays, and the site of interaction was localized to a cytoplasmic region of APLP1 containing the amino acid sequence motif Asn-Pro-x-Tyr (NPxY). NPxY motifs are involved in clathrin-mediated endocytosis, and they have been shown to bind to PI domains present in several proteins. This region of APLP1 is conserved among all members of the amyloid precursor family of proteins. Indeed, we found that Dab1 also interacts with amyloid precursor protein (APP) and APLP2 in biochemical association experiments. In transiently transfected cells, Dab1 and APLP1 colocalized in membrane ruffles and vesicular structures. Cotransfection assays in cultured cells indicated that APP family members increased serine phosphorylation of Dab1. Dab1 and APLP1 are expressed in similar cell populations in developing and adult brain tissue. These results suggest that Dab1 may function, at least in part, through association with APLP1 in the brain.

Key words: reeler; scrambler; neuronal migration; phosphorylation; APLP1; signal transduction
The mutant mouse strains reeler (Falconer, 1951), scrambler (Sweet et al., 1996), and yotari (Yoneshima et al., 1997) and the mouse strain created by targeted disruption of the disabled-1 (Dab1) gene (Howell et al., 1997a,b) exhibit motor defects and ataxia associated with severe hypoplasia of the cerebellum (for review, see D'Arcangelo and Curran, 1998; Goldowitz and Hamre, 1998). In these mice, neuronal migration is disrupted throughout the brain, resulting in disorganization of many laminar structures, including the hippocampus, cerebral cortex, and cerebellum. Similar, but not identical, defects have been reported in two mutant mouse strains created by targeted disruption of the genes for cyclin-dependent kinase 5 (Cdk5) and its neuronalspecific activator p35 (Ohshima et al., 1996; Chae et al., 1997). Characterization of the genes responsible for these mutations has provided a collection of molecules that participate in the signaling cascades responsible for choreographing neuronal migration in the developing brain. The task now facing the field is to understand how these proteins function and to elucidate their biochemical and biological relationships.

The gene disrupted in reeler mice, reelin (D'Arcangelo et al., 1995), encodes a large extracellular protein that is secreted by

\footnotetext{
Received May 10, 1999; revised June 22, 1999; accepted June 23, 1999.

This work was supported in part by National Institutes of Health Cancer Center Support Grant P30 CA21765, National Institute of Neurological Diseases and Stroke Grant R01-NS36558 (T.C.), National Institutes of Health Grant 5T32 CA09346 (D.S.R.), the American Lebanese Syrian Associated Charities, and Human Frontiers Science Program Grant RG67/98. We thank W. Wasco for providing APLP1 and APLP2; U. Müller for APP695; G. Thinakaran for CT11 anti-APLP1 antibodies; M. Vidal for providing the yeast two-hybrid system; P. McKinnon and M. Kapsetaki for advice and discussions; A. J. Diehl for assistance in phosphoamino acid analysis; and members of Curran lab for critically reading this manuscript.

Correspondence should be addressed to Tom Curran, Department of Developmental Neurobiology, St. Jude Children's Research Hospital, Memphis, TN 38105. Copyright (C) 1999 Society for Neuroscience $0270-6474 / 99 / 197507-09 \$ 05.00 / 0$
}

pioneer neurons in several regions of the developing brain (Ogawa et al., 1995; D’Arcangelo et al., 1997). In contrast, Dab1, which is disrupted in scrambler and yotari mice (Sheldon et al., 1997), encodes an intracellular protein with properties of an adapter molecule that functions in protein kinase signaling (Howell et al., 1997a). During development, reelin and Dab1 are expressed in adjacent cell populations before the time at which anatomical defects become apparent in the mutant mice (Rice et al., 1998). Furthermore, Dab1 accumulates in the neurons that go astray in reeler mice, suggesting that Reelin stimulates turnover of Dab1. These findings imply that Dab1 functions as a downstream component of a signaling pathway that is activated by Reelin.

The amino terminus of Dab1 contains a protein interaction (PI) domain (amino acids 1-170) that is structurally similar to the phosphotyrosine-binding (PTB) domain of Shc (Bork and Margolis, 1995; Howell et al., 1997a). PI-PTB domains have been shown to bind to the amino acid sequence motif Asn-Pro-x-Tyr (NPxY) (van der Geer and Pawson, 1995; Borg et al., 1996; Chien et al., 1998), as well as to acidic phospholipids (Zhou et al., 1995; Howell et al., 1999).

To identify proteins that bind to Dab1, we screened mouse embryonic and adult brain cDNA libraries using the yeast twohybrid system. Several proteins were found to interact with the PI domain of Dab1; however, the prevalent target identified was the mouse amyloid precursor-like protein 1 (APLP1). Biochemical studies confirmed this interaction and demonstrated that Dab1 binds to the C-terminal cytoplasmic region of APLP1. In transiently transfected cells, Dab1 partially colocalizes with APLP1 and increases in serine phosphorylation. In brain tissues, Dab1 and APLP1 are expressed in overlapping cell populations. These results imply that Dab1 may function, in part, through association with APLP1. 


\section{MATERIALS AND METHODS}

Yeast two-hybrid system. We used the modified yeast two-hybrid system described by Vidal et al. (1996). In this system, interaction of a bait fusion protein with a cDNA fusion protein results in GAL4-dependent transcription activation of $H I S 3, U R A 3$, and $L a c Z$ reporter genes. The yeast strain Mav103 was first transformed with the vector pPC97-myc, encoding a GAL4 DNA binding (DB) domain fused to the Dab1 PI domain and a myc-epitope tag. An expression library comprising cDNAs fused to the GAL4 activation domain (AD) in the pPC86 vector was then introduced into these cells using a high-efficiency lithium acetate procedure (Kaiser et al., 1994). Transformed colonies were propagated on synthetic complete media lacking leucine and tryptophan. Potential interacting clones were first selected for the ability to grow on media lacking leucine, tryptophan, and histidine in the presence of $40 \mathrm{~mm} 3$-aminotriazole (3-AT), a dose-dependent inhibitor of the HIS3 gene product. After $4 \mathrm{~d}$ of incubation at $30^{\circ} \mathrm{C}$, positive colonies were selected further by their ability to grow in the presence of increasing concentrations of 3-AT (60, 80 , and $100 \mathrm{~mm}$ ) to express $\beta$-galactosidase and to grow in the absence of uracil. This stringent selection protocol ensured the identification of bona fide Dab1-interacting clones. Plasmids were isolated from clones that were positive in all three assays and then analyzed by DNA sequencing.

Generation of constructs. The pPC97 vector was modified to contain a myc-epitope tag sequence downstream of the GAL4 DB by ligating synthetic oligonucleotides encoding the myc-epitope tag sequence to pPC97 (Vidal et al., 1996). The N-terminal fragment of Dab1 (amino acids 1-179) was amplified by PCR and subcloned in-frame between the GAL4 DB and the myc-epitope tag in pPC97-myc vector. For expression in mammalian cells, the PI-myc DNA was excised from pPC97-myc vector and subcloned into pcDNA3.1/HIS (Invitrogen, San Diego, CA). Full-length mouse cDNA for APLP1, APLP2 (kindly provided by W. Wasco, Massachusetts General Hospital, Charlestown, MA), and amyloid precursor protein $695\left(\mathrm{APP}_{695}\right)$ (kindly provided by U. Müller, Max-Planck Institute, Frankfurt, Germany) were subcloned in the mammalian expression vector pcDNA3 (Invitrogen). Full-length Dab1 was amplified by PCR using a downstream primer containing the sequence to hemagglutinin (HA) epitope tag and then cloned in pcDNA3.1/HIS (Invitrogen). The glutathione $S$-transferase (GST)-Dab1 fusion construct was made by subcloning full-length Dab1 in pGEX4T3 (Pharmacia, Piscataway, NJ).

cDNA libraries. The PI domain of Dab1 was used to screen both the ProQuest two-hybrid mouse brain cDNA library (Life Technologies, Gaithersburg, MD) and an embryonic day 14.5 (E14.5) head cDNA library. To generate the embryonic library, $\operatorname{poly}\left(\mathrm{A}^{+}\right)$RNA from E14.5 mouse heads was prepared using the RNA FastTrack 2.0 kit (Invitrogen). Oligo-dT primed double-stranded cDNA was synthesized, ligated with SalI adapters, and fractionated by size using the SuperScript Plasmid System for cDNA Synthesis and Plasmid Cloning kit (Life Technologies). cDNAs of $>500 \mathrm{bp}$ were subcloned directionally in pPC86 and propagated in Escherichia coli ElecroMAX DH10B cells (Life Technologies). Plasmids from 20 random colonies were all found to contain inserts ranging in size from 0.8 to $4.5 \mathrm{~kb}$. Approximately $0.9 \times 10^{6}$ primary colonies were pooled to prepare a library of plasmid DNA.

In vitro translation and binding assay. The positive clone APLP1 $1_{219-653}$ was PCR amplified using Elongase polymerase (Life Technologies) and primers to the plasmid sequences flanking the cloning site. The upstream primer corresponds to the GAL4 AD sequence in pPC86 vector, and it contained a nested T7 promoter sequence and a consensus sequence for translation initiation. The PCR product was purified using the QIAquick PCR purification kit (Qiagen, Hilden, Germany) and used in the TNT T7 Quick Coupled Transcription/Translation System (Promega, Madison, $\mathrm{WI})$ in the presence of $20 \mu \mathrm{Ci} / \mathrm{ml}\left[{ }^{35} \mathrm{~S}\right]$ methionine and $\left[{ }^{35} \mathrm{~S}\right]$ cysteine labeling mix ( $>1000 \mathrm{Ci} / \mathrm{mmol}$; NEN, Boston, MA).

To isolate pure GST-Dab1, BL21 bacterial strain was transformed with full-length Dab1 in pGEX4T3 vector (Pharmacia) and propagated at $37^{\circ} \mathrm{C}$ to optical density $(600 \mathrm{~nm})$ of $0.4-0.6$. Protein expression was induced overnight at $18^{\circ} \mathrm{C}$ with $0.1 \mathrm{~mm}$ isopropyl- $\beta$-D-thiogalactopyranoside. The cells were lysed in TX-LB (30 mM HEPES, pH 7.5, $1 \%$ Triton $\mathrm{X}-100,10 \%$ glycerin, $150 \mathrm{~mm} \mathrm{NaCl}, 5 \mathrm{~mm} \mathrm{MgCl}, 1 \mathrm{~mm}$ sodium vanadate, $25 \mathrm{~mm}$ sodium fluoride, $1 \mathrm{~mm}$ EGTA, $10 \mu \mathrm{g} / \mathrm{ml}$ aprotinin, $10 \mu \mathrm{g} / \mathrm{ml}$ leupeptin, $10 \mu \mathrm{g} / \mathrm{ml}$ trypsin inhibitor, $10 \mu \mathrm{g} / \mathrm{ml}$ pepstatin, $2 \mathrm{~mm}$ phenylmethylsulfonyl fluoride, and $0.1 \%$ 2-mercaptoethanol), sonicated $30 \mathrm{sec}$ at $4^{\circ} \mathrm{C}$, and stored at $-80^{\circ} \mathrm{C}$. The GST-Dab1 fusion protein was purified using glutathione-Sepharose (Pharmacia). Labeled in vitro translated proteins (APLP1 $1_{219-653}, \mathrm{APLP}_{219-640}, \mathrm{APLP} 1, \mathrm{APLP} 2$, and $\mathrm{APP}_{695}$ ) were incubated with $0.1 \mu \mathrm{M}$ glutathione-Sepharose-bound GST-Dab1 protein in TX-LB for $2 \mathrm{hr}$ at $4^{\circ} \mathrm{C}$. For peptide competition experiments, $0.8 \mu \mathrm{M}$ glutathione-Sepharose-bound GST-Dab1 protein was incubated with $0,0.8,8.0$, or $80 \mu \mathrm{M}$ of either competitor peptide APLP1-C18 (CELQRHGYENPTYRFLEE) or the control randomized peptide (CFEYRNRHQETPELLGEY) in TX-LB buffer for $1 \mathrm{hr}$ at $4^{\circ} \mathrm{C}$ before incubation with in vitro translated APLP1. The GST-Dab1 complexes were washed three times in radioimmunoprecipitation assay (RIPA) buffer $(150 \mathrm{~mm} \mathrm{NaCl}, 1 \% \mathrm{NP}-40,0.5 \%$ deoxycholate, $0.1 \%$ SDS, and 50 mM Tris, $\mathrm{pH} 8.0$ ), eluted in $2 \times$ SDS sample buffer, separated by SDSPAGE, and examined by fluorography.

Cell culture, ${ }^{32} P$-labeling, immunoprecipitation, and phosphoamino acid analysis. COS7 cells were maintained in DMEM (BioWhittaker, Walkersville, MD) supplemented with 5\% fetal bovine serum (Hyclone, Logan, UT), $10 \mathrm{U} / \mathrm{ml}$ penicillin-streptomycin mixture (Life Technologies), and $2 \mathrm{~mm}$ GlutaMAX (Life Technologies) at $37^{\circ} \mathrm{C}$ under $5 \% \mathrm{CO}_{2}$. Cells were transfected with appropriate constructs in pcDNA3 vector (Invitrogen) or pcDNA3.1/His (Invitrogen) using Superfect transfection reagent (Qiagen). Two days after the transfection, the cells were labeled for $2 \mathrm{hr}$ in the presence of $0.5 \mathrm{mCi} / \mathrm{ml}\left[{ }^{32} \mathrm{P}\right]$ orthophosphate (NEN) in phosphate-free DMEM supplemented with 5\% serum, antibiotics, and glutamine as described above. Proteins were extracted in TX-LB and incubated with a monoclonal antibody to HA epitope tag (clone 16B12, Babco, Richmond, CA) at $4^{\circ} \mathrm{C}$ for $2 \mathrm{hr}$. Immune complexes were collected with protein G-agarose beads (Pierce, Rockford, IL) and washed three times in RIPA buffer supplemented with $10 \mu \mathrm{g} / \mathrm{ml}$ aprotinin, 10 $\mu \mathrm{g} / \mathrm{ml}$ leupeptin, $10 \mu \mathrm{g} / \mathrm{ml}$ trypsin inhibitor, $10 \mu \mathrm{g} / \mathrm{ml}$ pepstatin, $2 \mathrm{mM}$ phenylmethylsulfonyl fluoride, and $0.1 \%$ 2-mercaptoethanol. Immunoprecipitates were eluted in SDS sample buffer, separated by SDS-PAGE, blotted to nitrocellulose membranes, and examined by autoradiography. ${ }^{32} \mathrm{P}$-labeled Dab1 was excised from the membrane and hydrolyzed in $6 \mathrm{~N}$ $\mathrm{HCl}$ at $100^{\circ} \mathrm{C}$ for $1 \mathrm{hr}$. Amino acids were separated using the Hunter Thin Layer Electrophoresis System (HTLE-7000; CBS Scientific Company, Solana Beach, CA).

Coimmunoprecipitation and Western blotting. Proteins from transfected COS7 cells were extracted in TX-LB and immunoprecipitated with anti-HA antibody (clone 16B12; Babco) or with anti-myc antibody (clone 9E10; Babco) as described above. The immunoprecipitates were eluted in SDS sample buffer, separated by SDS-PAGE, and blotted onto nitrocellulose membranes. The membranes were blocked overnight at $4^{\circ} \mathrm{C}$ in $5 \%$ nonfat dry milk in TBST (50 mM Tris, pH 7.4, $150 \mathrm{~mm} \mathrm{NaCl}$, and $1 \%$ Tween 20) and then treated with rabbit anti-APLP1 polyclonal antibodies CT11 (kindly provided by G. Thinakaran, The Johns Hopkins University School of Medicine, Baltimore, MD) for $2 \mathrm{hr}$ at $25^{\circ} \mathrm{C}$. Immune complexes were detected using the BM Chemiluminescence Western Blotting kit (Boehringer Mannheim, Indianapolis, IN).

Immunocytochemistry. COS-7 cells were transfected with HA-Dab1, full-length APLP1, or HA-Dab1 plus APLP1. One day after transfection, the cells were plated on four-chamber polystyrene glass slides (Falcon 4104). On the next day, the cells were fixed with $4 \%$ paraformaldehyde in PBS, permeabilized with $0.1 \%$ Triton X-100 in PBS, and blocked with $2.5 \%$ horse serum in PBS. The cells were incubated with monoclonal anti-HA antibody (Babco) and rabbit polyclonal anti-APLP1 antibody CT11 for $2 \mathrm{hr}$ at $25^{\circ} \mathrm{C}$. After washing, the cells were treated with fluorescein-conjugated anti-mouse (Vector Laboratories, Burlingame, $\mathrm{CA}$ ) and Texas Red-X-conjugated anti-rabbit (Molecular Probes, Eugene, OR) antibodies. Fluorescence was visualized by a Leica (Nussloch, Germany) IRBE Confocal Microscope with $63 \times 1.4$ oil immersion objective.

In situ hybridization. Tissue collection, fixation, and hybridization analysis was performed as described by Rice et al. (1998). Riboprobes were labeled with ${ }^{33} \mathrm{P}$-UTP $(50 \mu \mathrm{Ci})$ by in vitro transcription of amplified DNA products corresponding to the $3^{\prime}$ untranslated region of Dab1 (nucleotides 1935-2116) and the coding region of APLP1 (nucleotides 657-913). Slides were counterstained with $0.1 \%$ toluidine blue and examined on an Olympus Opticals (Tokyo, Japan) BX60 microscope, and images were acquired with a Hamamatsu (Tokyo, Japan) C5810 video camera.

\section{RESULTS \\ Dab1 interacts specifically with the cytoplasmic domain of APLP1}

Dab1-interacting proteins were identified in a yeast two-hybrid system in which three different reporter genes were used to select 
(A)

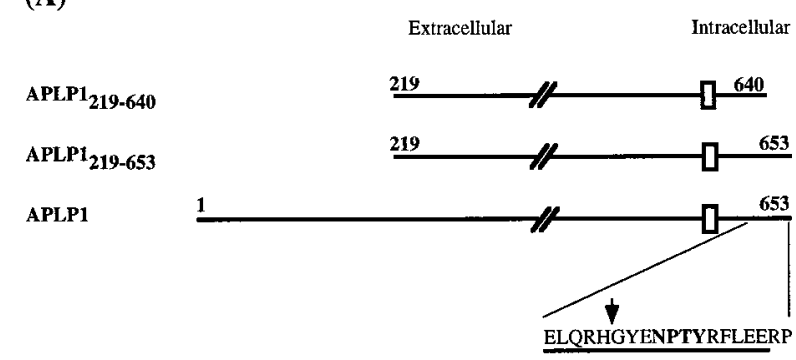

(B)

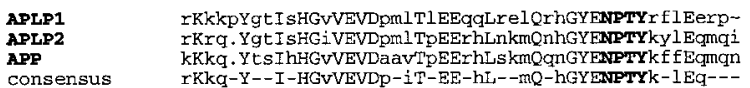

Figure 1. Schematic representation of APLP1 and alignment of the cytoplasmic domains of APLP1, APLP2, and APP. A, APLP1 is a 653 amino acid protein that contains a single transmembrane domain (open box). The site of the C-terminal truncation of APLP1 (APLP1 $219-640$ ) is indicated by the arrow. The sequence corresponding to the synthetic peptide APLP1-C18 is underlined. B, Alignment of the cytoplasmic domains of APLP1, APLP2, and APP was obtained using the PILEUP program (Genetics Computer Group, Madison, WI). Amino acids that are identical and conservatively substituted in all three sequences are indicated by uppercase and lowercase letters, respectively. The NPxY internalization-PI-interacting motif is indicated by bold letters.

positive clones. Approximately $5 \times 10^{5}$ clones from an embryonic head or from an adult brain cDNA library were screened using the PI domain of Dab1. Potential interacting clones were first identified by growth selection on media lacking histidine. Positive clones were then tested for their ability to grow in the absence of uracil and to express $\beta$-galactosidase activity. We selected only clones that scored positive in all three assays. Nucleotide sequence analysis identified several different classes of genes that interacted with the PI domain of Dab1. The most prevalent gene among this collection was APLP1, which represented 6 of 45 $(13 \%)$ positive clones identified in the embryonic library screen and 26 of $42(62 \%)$ positive clones identified in the adult library screen. APLP1 is a single-spanning transmembrane protein with a large extracellular domain and a small C-terminal cytoplasmic domain (Fig. 1A) (Wasco et al., 1992). All of the Dab1interacting clones contained the C-terminal domain of APLP1 and various portions of the extracellular domain, suggesting that the site of Dab1 interaction was located in the cytoplasmic region. We selected the largest clone, which comprised 434 C-terminal amino acids of APLP1 (APLP1 $\left.1_{219-653}\right)$, for subsequent experiments.

To confirm the interaction between APLP1 $1_{219-653}$ and Dab1, we performed biochemical protein association experiments using full-length GST-Dab1. APLP1 $1_{219-653}$ was synthesized in vitro and incubated with GST-Dab1 immobilized on glutathione beads. After washing, protein complexes were eluted and analyzed by autoradiography. As shown in Figure $2 A$, APLP1 $1_{219-653}$ interacted specifically with GST-Dab1 and not with GST alone. Examination of the amino acid sequence in the cytoplasmic domain of APLP1 revealed a conserved NPxY motif (Fig. 1B). The NPxY motif was first described as an amino acid sequence required for clathrin-mediated endocytosis of the low-density lipoprotein receptor (Chen et al., 1990) and later as a binding site for Shc and other cytoplasmic proteins containing PI domains (van der Geer and Pawson, 1995; Borg et al., 1996). To determine whether Dab1 binds to the NPxY region of APLP1, we constructed a deletion mutant lacking a 14 amino acid $\mathrm{C}$-terminal
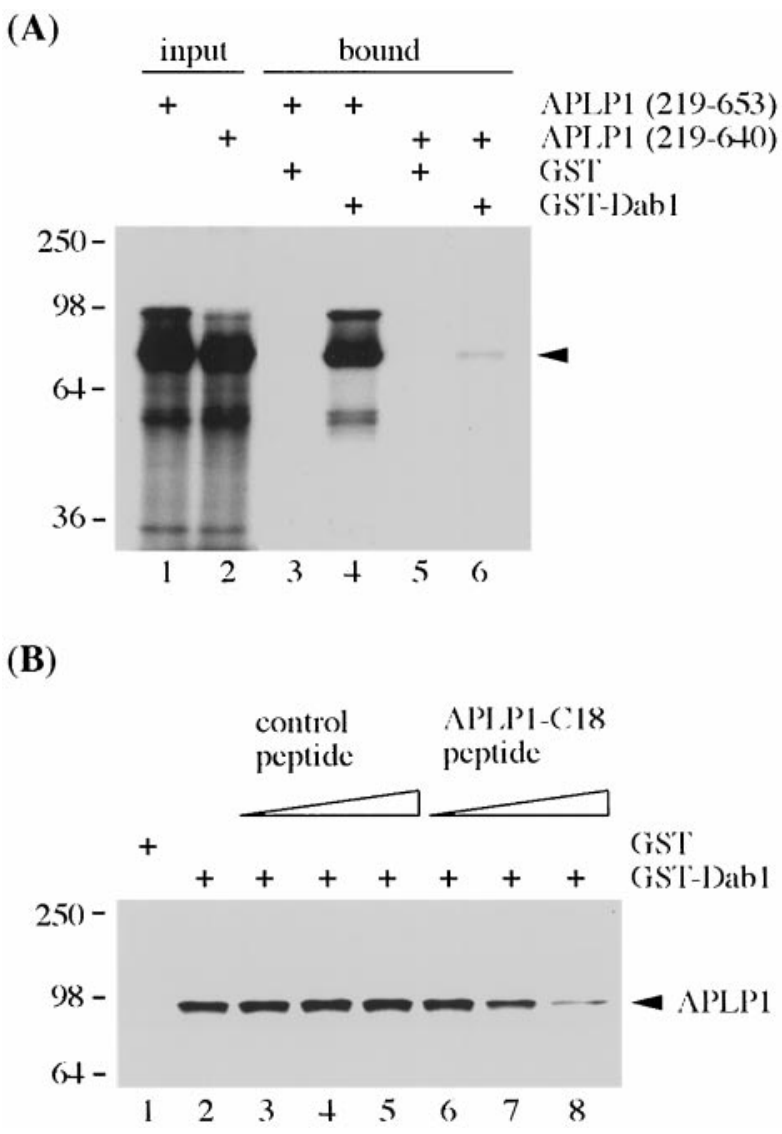

Figure 2. Dab1 binds specifically to the cytoplasmic domain of APLP1. $A$, Proteins corresponding to APLP1 $1_{219-653}$ (lane 1 ) and a C-terminal truncation APLP1 $1_{219-640}$ (lane 2 ) were synthesized in vitro and incubated with GST alone (lanes 3, 5) or with GST-Dab1 (lanes 4, 6) immobilized on glutathione-Sepharose beads. The lanes marked input contain $10 \%$ of the translation products loaded onto the beads. Protein complexes were washed in RIPA buffer, subjected to SDS-PAGE, and visualized by autoradiography. $B$, GST-Dab1 immobilized on glutathione-Sepharose beads was preincubated with increasing concentrations $(1,10$, and $100 \times$ molar excess) of a competitor peptide APLP1-C18 (lanes 6-8) or a control randomized peptide (lanes 3-5) before the addition of in vitro synthesized full-length APLP1. As a control, GST (lane 1) or GST-Dab1 (lane 2) were incubated with in vitro synthesized APLP1 in the absence of any peptides.

region of APLP1 containing the NPxY motif (APLP1 $1_{219-640}$ ) (Fig. 1A). This mutant protein failed to bind Dab1 in protein association assays (Fig. $2 A$ ), indicating that amino acids 640-653 are required for the interaction. Similarly, in competition studies, a synthetic peptide corresponding to amino acids 635-651 of APLP1 (APLP1-C18) inhibited binding of Dab1 to APLP1 (Fig. $2 B)$. A control peptide with the same amino acid content arranged in random order had no effect on the Dab1-APLP1 association. Together, these results indicate that Dab1 binds specifically to a C-terminal region of APLP1 containing an NPXY motif.

The experiments described above show that Dab1 binds to APLP1 in yeast cells and in cell-free extracts. To determine whether Dab1 associates with APLP1 in intact mammalian cells, we performed coexpression studies in transfected cells. Epitopetagged versions of the Dab1 PI domain (myc-Dab1 $1_{1-179}$ ) and full-length Dab1 (HA-Dab1) were introduced together with APLP1 into COS cells by transfection. As shown in Figure $3 A$, immunoprecipitation of myc-Dab $1_{1-179}$ using myc epitope anti- 


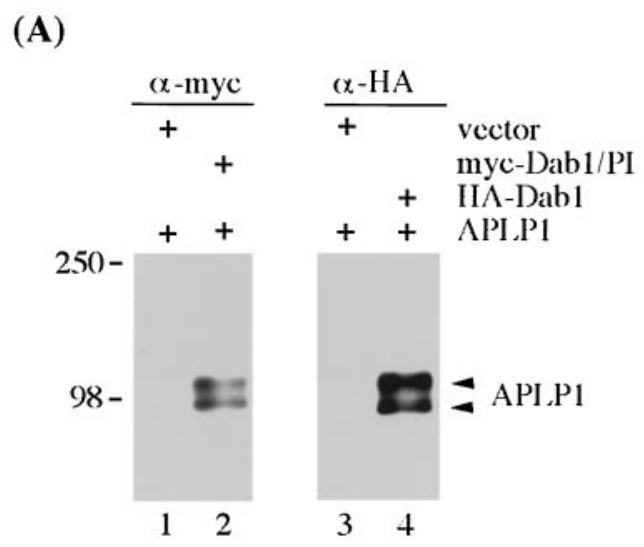

(B)

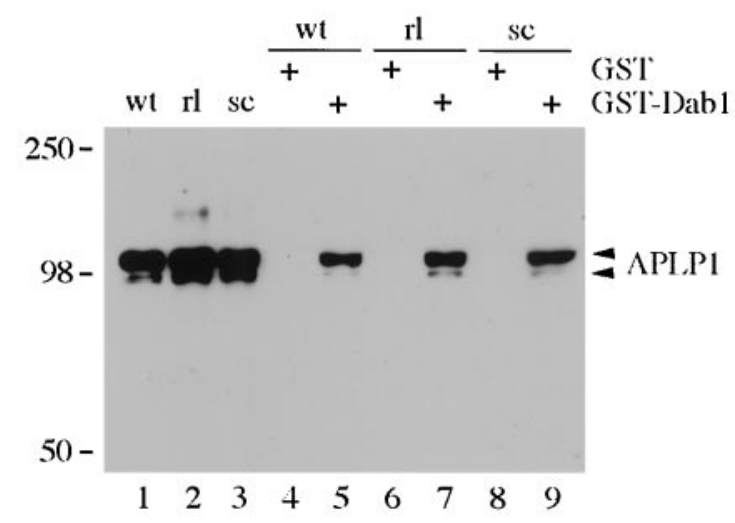

Figure 3. Dab1 interacts with APLP1 in COS cells and in brain extracts. $A$, COS cells were transfected with APLP1 along with control vector (lanes 1, 3), myc-tagged Dab1-PI domain (lane 2), or HA-tagged Dab1 (lane 4). Dab1-PI and full-length Dab1 were immunoprecipitated using anti-myc and anti-HA antibodies, respectively. The immunoprecipitates were washed in RIPA buffer, subjected to SDS-PAGE, and immunoblotted with the anti-APLP1 antibody CT11. $B$, Brain extract $(100 \mu \mathrm{g})$ from wild-type $(w t)$, reeler $(r l)$, or scrambler $(s c)$ mice were incubated with GST alone (lanes 4, 6, 8) or with GST-Dab1 (lanes 5, 7, 9). Protein complexes were washed in RIPA buffer, subjected to SDS-PAGE, and immunoblotted with the anti-APLP1 antibody CT11. Brain homogenates (20 $\mu \mathrm{g})$ from wild-type, reeler, or scrambler mice were also loaded on the gel (lanes 1-3).

bodies and HA-Dab1 using HA epitope antibodies resulted in coprecipitation of APLP1. This implies that Dab1 binds to APLP1 in vivo through its PI domain.

To determine whether APLP1 in the brain can interact with Dab1, we incubated normal brain extracts with GST-Dab1 immobilized on glutathione-Sepharose beads. The protein complexes were washed under stringent buffer conditions and then analyzed for the presence of APLP1 by immunoblotting. As shown in Figure $3 B$, Dab1 was found to bind to APLP1 present in normal brain extracts. We have attempted to coimmunoprecipitate Dab1 and APLP1 from brain lysates with no success. Unfortunately, the interaction domains of Dab1 (PTB) and APLP1 (NPxY) contain the epitopes for the only antisera available for these proteins. In fact, in vitro studies indicate that these antibodies actually inhibit protein-protein association (data not shown).

Dab1 functions as a downstream component of a signal transduction pathway involving Reelin that controls cell positioning in

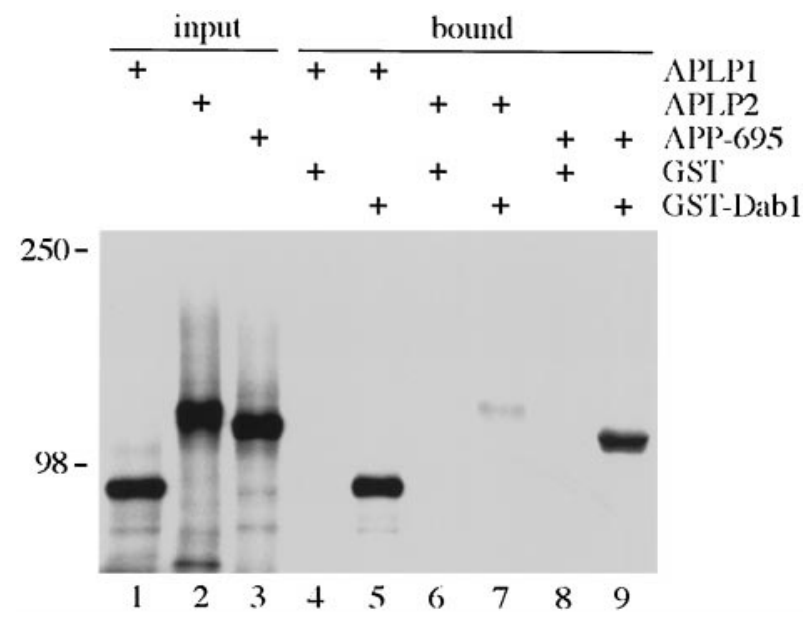

Figure 4. Dab1 interacts with all members of the APP family. Full-length APLP1 (lane 1), APLP2 (lane 2), and $\mathrm{APP}_{695}$ (lane 3) were synthesized in vitro and incubated with GST alone (lanes 4, 6, 8) or with GST-Dab1 (lanes 5, 7, 9) immobilized on glutathione-Sepharose beads. The lanes marked input contain $10 \%$ of the translation products loaded onto the beads. The bound proteins were washed in RIPA buffer, subjected to SDS-PAGE, and visualized by autoradiography.

the developing brain. This pathway is disrupted in reeler and scrambler mice, which are deficient in Reelin and Dab1 expression, respectively. To determine whether this disruption affects the ability of APLP1 to bind to Dab1, we examined whether the binding of APLP1 to Dab1 was affected in the mutant mice. No difference in the amount of APLP1 binding was seen using protein extracts from reeler and scrambler brain tissue (Fig. 3B). These results indicate that Dab1 associates with APLP1 in the brain of normal, as well as mutant, mice.

\section{All APP-like proteins bind to Dab1}

APLP1 is a member of the family of proteins including APP (Kang et al., 1987) and APLP2 (Wasco et al., 1993). The protein products of these genes, including the alternatively spliced variants of APP and APLP2, all contain a large $N$-glycosylated extracellular domain, a transmembrane domain, and a small $(\sim 47$ amino acids) C-terminal cytoplasmic domain. Only APP contains the $\beta$-amyloid peptide sequence that is found in amyloid plaques associated with Alzheimer's disease. These proteins exhibit an overall amino acid sequence identity of $36-52 \%$. The most striking region of similarity among the APP proteins is the cytoplasmic domain, particularly the region containing the NPxY internalization-PI-binding motif (Fig. 1B). Surprisingly, none of the PI-interacting clones in our yeast two-hybrid screens encoded either APP or APLP2. However, another group has identified APP in a yeast two-hybrid screen using the PI domain of Dab1 (Howell et al., 1999). Furthermore, Trommsdorff et al. (1998) recently described an interaction between the PI domain of Dab1 and the cytoplasmic domain of APP. Therefore, we compared the ability of Dab1 to associate with all APP family members. We found that Dab1-GST can bind to all three members of the APP family, although with different relative affinities (Fig. 4). Dab1 binds most efficiently to APLP1 and less efficiently to APP. In contrast, the binding of Dab1 to APLP2 was very weak. This suggests that amino acid sequences other than the conserved NPxY motif influence the binding specificity of Dab1 to APP family members. 
(A)

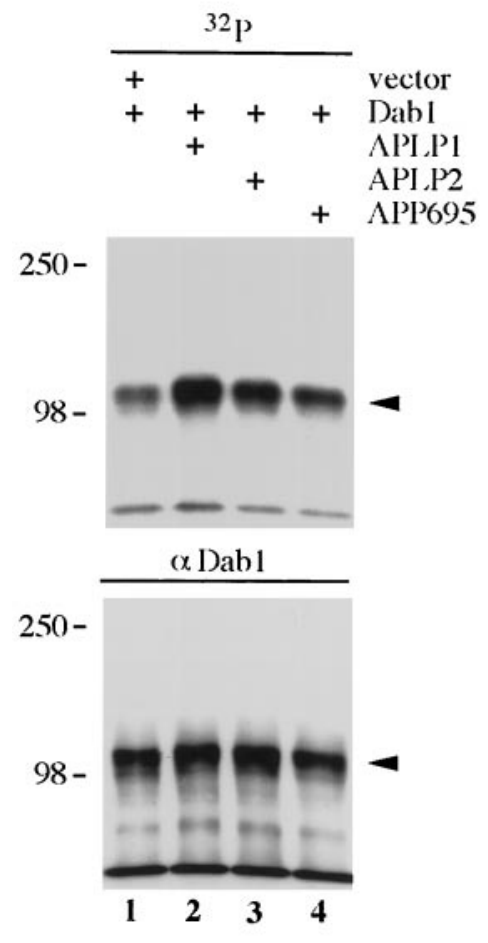

(B)

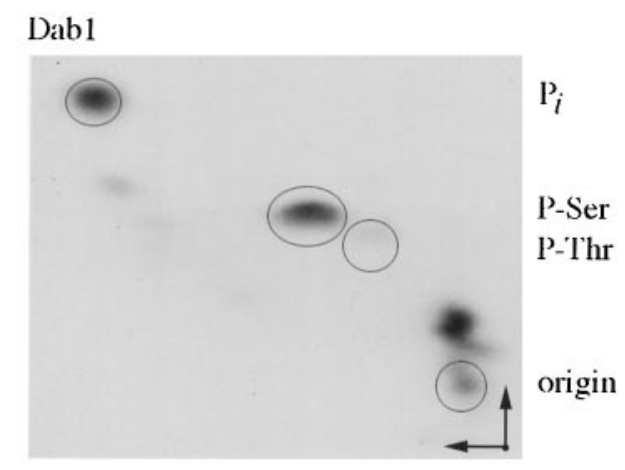

Dab1 + APLP1

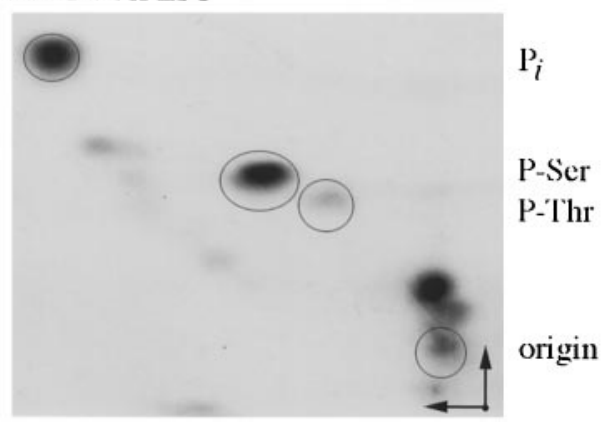

Figure 5. APLP1, APLP2, and APP increase serine phosphorylation of Dab1 in COS cells. A, COS cells were transfected with HA-tagged Dab1 plus vector (lane 1), APLP1 (lane 2), APLP2 (lane 3), or APP 695 (lane 4). Two days after transfection, the cells were labeled with $\left[{ }^{32} \mathrm{P}\right]$ orthophosphate. Dab1 was immunoprecipitated and blotted onto a nitrocellulose membrane. The membrane was exposed to film (top) and then immunoblotted using an antibody to Dab1 (bottom). B, Phosphoamino acid analysis of immunoprecipitated Dab1 from $\left[{ }^{32} \mathrm{P}\right]$-labeled COS cells cotransfected with Dab1 and vector (top) or Dab1 and APLP1 (bottom). The position of the origin, phosphoserine $(P-S e r)$, phosphothreonine $(P-T h r)$, and unincorporated inorganic phosphate $\left(P_{i}\right)$ is indicated.

\section{APLP1 increases serine phosphorylation of Dab1 in cultured cells}

In coimmunoprecipitation experiments using cultured cells, we detected a retardation in the mobility of Dab1 in polyacrylamide gels when Dab1 was expressed together with APLP1. Such band shifts are sometimes caused by phosphorylation of proteins. To explore this possibility, COS cells transfected with Dab1 alone or with APLP1, APLP2, or APP were labeled with $\left[{ }^{32} \mathrm{P}\right]$ orthophosphate. Dab1 was immunoprecipitated, and the extent of phosphorylation was determined by autoradiography. We found that the phosphorylation level of Dab1 increased twofold to threefold in the presence of APLP1, APLP2, or APP, whereas the level of Dab1 protein remained unchanged (Fig. $5 A$ ). In addition, by pulse-chase analysis, we did not observe any effect of APLP1 on the stability of Dab1 in transfected COS cells (data not shown). These results indicate that APLP1 increases the phosphorylation of Dab1 in cultured cells.

To investigate the nature of APLP1-induced Dab1 phosphorylation, we performed phosphoamino acid analysis. The results indicate that expression of APLP1 specifically increases serine phosphorylation of Dab1 (Fig. 5B). These observations suggest that there is a functional interaction between APP family members and Dab1 in mammalian cells. Although the biological significance of this phosphorylation event remains to be determined, it may play a role in regulating the function of Dab1 in signaling cascades.

\section{Dab1 colocalizes with APLP1 in cultured cells}

We used confocal laser microscopy to examine the subcellular distribution of Dab1 and APLP1 in transiently transfected COS-7 cells. In single transfected cells, strong Dab1 staining was detected throughout the cytosol, and weaker staining was detected in membrane ruffles and in perinuclear regions (Fig. 6A). On the other hand, APLP1 showed strong perinuclear staining, presum- ably including the endoplasmic reticulum and Golgi apparatus (Fig. 6B). When highly expressed, APLP1 appeared in large vesicular structures throughout the cytoplasm. In cells that were transfected with both Dab1 and APLP1, an overlap in staining patterns was detected in the membrane ruffles (Fig. $6 F$ ), as well as in the vesicular structures (Fig. 6G). These results provide additional support that Dab1 and APLP1 interact in cells.

\section{Dab1 and APLP1 are expressed in similar cell populations in embryonic and adult brain}

APP family genes are expressed in distinct temporal and spatial patterns during development (Lorent et al., 1995). APP and APLP2 mRNA levels increase progressively in a wide range of tissues from E10 to birth. In contrast, APLP1 is almost exclusively restricted to the developing CNS and peripheral nervous system. During embryogenesis, there is a dramatic increase in the expression of APLP1 between E10 and E13, when the nervous system is undergoing rapid expansion. In the adult brain, the expression levels of APLP1 remain high.

Dab1 is expressed in neurons at early times during development of the CNS (Howell et al., 1997a; Rice et al., 1998). To determine whether Dab1 and APLP1 are expressed in similar cell populations, we compared their expression patterns in the developing and mature brain by in situ hybridization. At E15, three layers can be easily distinguished in the developing cerebral cortex. The ventricular zone, which contains proliferating cells, is located near the lumen of the telencephalon. The intermediate zone lies just above the ventricular zone, and it is traversed by cells as they exit the cell cycle and migrate toward the cortical plate near the surface of the brain. Gradually, the cortical plate becomes populated with neurons that differentiate, forming the mature cerebral cortex. At this time, both Dab1 and APLP1 are expressed at high levels in the cortical plate (Fig. 7A,B). Dab1 and $A P L P 1$ are also expressed in the intermediate and ventricular 

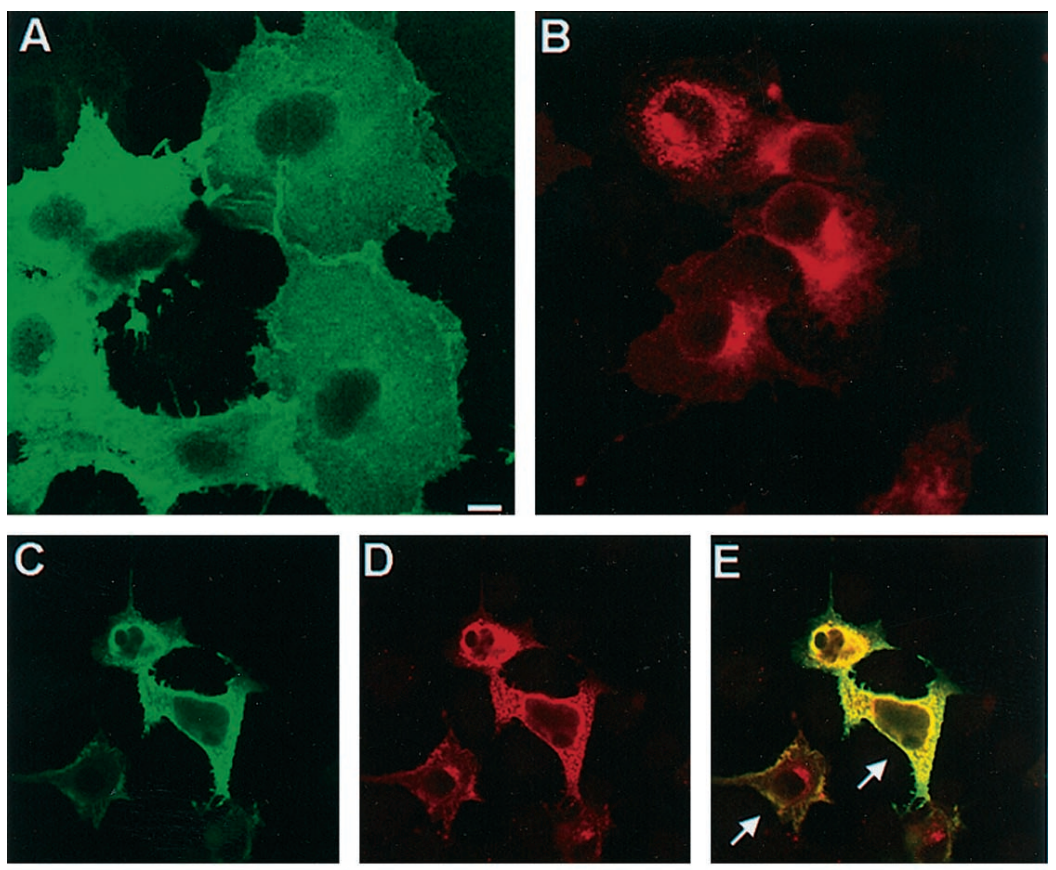

Figure 6. Subcellular distribution of Dab1 and APLP1 in COS-7 cells. Immunofluorescence confocal microscopy of COS-7 cells transfected with HA-Dab1 $(A)$, APLP1 $(B)$, or HA-Dab1 plus APLP1 $(C-G)$. Dab1 staining is detected throughout the cytosol, in membrane ruffles, and perinuclear regions (green; $A, C$ ), whereas APLP1 staining is primarily perinuclear and in vesicular structures $(\mathrm{red} ; B, D)$. Overlay of the staining patterns reveals that Dab1 and APLP1 colocalize in membrane ruffles and in vesicular structures ( yellow; $E-G)$. $F$ and $G$ show a 2 and $4 \times$ magnification of cells in $E$, respectively. Scale bar, $10 \mu \mathrm{m}$.
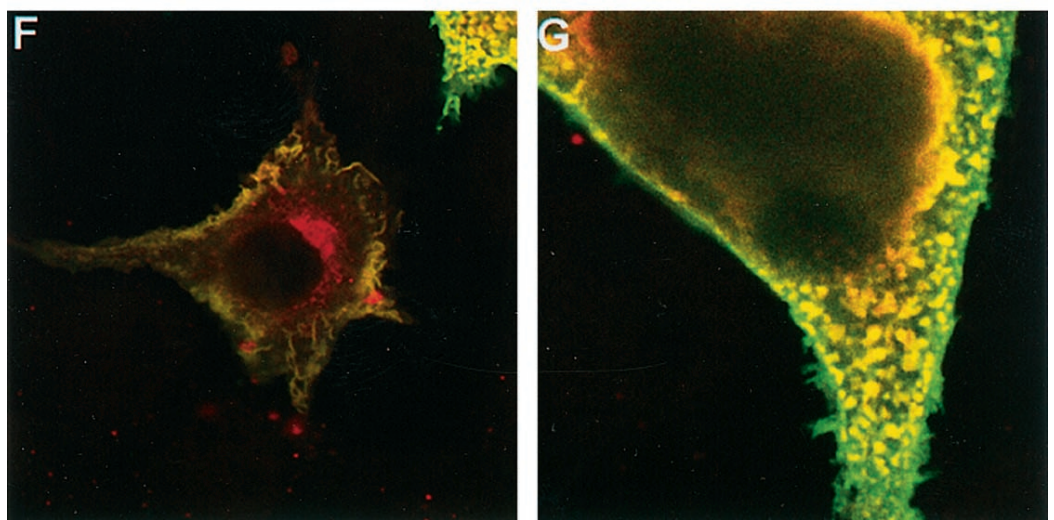

zones, albeit at lower levels compared with the cortical plate. Thus, during formation of the cerebral cortex, both Dab1 and $A P L P 1$ are expressed in regions containing migratory and postmigratory neurons.

In the mature brain, Dab1 and APLP1 are expressed in the dentate gyrus and in pyramidal cells in regions CA1-CA3 of the hippocampus proper (Fig. $7 E, F$ ). The expression of $A P L P 1$ in adult brain is more widespread than that of $D a b 1$. For example, APLP1 is expressed in the fornix, a myelinated pathway of the hippocampus, indicating that glial cells also express this gene (Fig. $7 F$, asterisk). Control probes showed no specific hybridization (Fig. 7D,H). These results demonstrate that Dab1 and APLP1 expression overlaps in many neuronal populations in the developing and adult brain.

\section{DISCUSSION}

Here, we identify APLP1 as a Dab1-interacting protein using the yeast two-hybrid system. The sites of interaction correspond to the PI domain of Dab1 and a conserved cytoplasmic NPxY motif in APLP1. Although Dab1 interacts with APP and APLP2, comparative binding studies indicate that Dab1 associates preferentially with APLP1. In transfected cells, all APP family members caused an increase in serine phosphorylation of Dab1. In addition, Dab1 and APLP1 colocalized in membrane ruffles and in vesicular structures. Dab1 and APLP1 were found to be coexpressed in many populations of neurons in developing and adult brain tissues. Together, these results suggest that Dab1 and APP family members may function together in signal transduction pathways in neurons.

The PI domain of Dab1 is structurally similar to the PTB domain of the Shc adapter protein (Bork and Margolis, 1995). The interaction of the Shc PTB domain with the NPxY sequence requires phosphorylation of the tyrosine residue in the motif (van der Geer et al., 1996). However, our results suggest that the PI domain of Dab1 binds to a nonphosphorylated NPxY motif. This is consistent with other studies showing that the PI-containing proteins FE65 and X11 also bind to the NPxY motif of APP in the absence of tyrosine phosphorylation (Borg et al., 1996). Mutation of the tyrosine to alanine in the NPxY motif did not affect binding of FE65 or X11 to the cytoplasmic domain of APP proteins. Furthermore, Howell et al. (1999) recently demonstrated that phosphorylation of the tyrosine in the NPxY motif inhibited binding of Dab1. Thus, it seems that Dab1, FE65, and X11 comprise a subclass of PTB-PI family proteins that bind to unmodified NPxY sequences. Comparative binding studies demonstrated that the PI domains of FE65, Dab1, and Dab2 (also known as mitogen-responsive protein p96) have different binding 

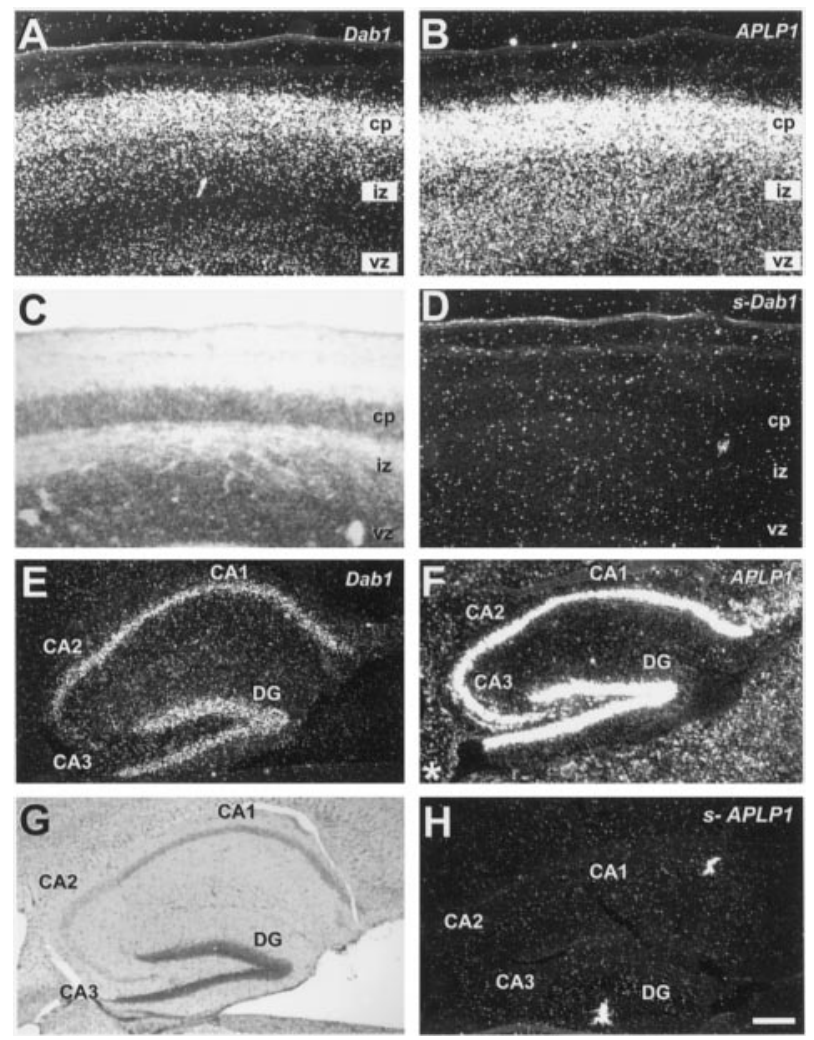

Figure 7. Expression of Dab1 and APLP1 in E15 cerebral cortex and adult hippocampus. $A$, Dark-field of a coronal section through the cerebral cortex hybridized with a Dab1 antisense probe. Dab1 is expressed in the cortical plate $(c p)$, intermediate zone $(i z)$, and ventricular zone $(v z) . B$, An adjacent section to that shown in $A$ was hybridized with an APLP1 antisense probe. $A P L P 1$ is expressed at higher levels and in similar regions to $D a b 1$. $C$, Bright-field of an adjacent section to that shown in $B$. $D$, Dark-field of the section shown in $C$ hybridized with a sense $D a b 1$ riboprobe ( $s-D a b 1)$. Compared with $A$, there is no specific hybridization with this probe. $E$, Dark-field of the adult hippocampus in sagittal section hybridized with a Dabl antisense probe. Dab1 is expressed in the dentate gyrus $(D G)$ and in regions CA1-CA3 of the hippocampus proper. $F, \mathrm{~A}$ neighboring section to that shown in $E$ was hybridized with an APLP1 antisense probe. $A P L P 1$ is expressed in the dentate gyrus and in CA1-CA3. In addition, $A P L P 1$ is expressed in other regions, such as the fornix (asterisk). $G$, Bright-field of the section shown in $E$ in dark-field. $H$, Dark-field of a neighboring section that was hybridized with a sense $A P L P 1$ riboprobe ( $s-A P L P 1)$. Compared with $F$, there is no specific hybridization with this probe. Scale bar (in $H$ ): $A-D, \sim 100 \mu \mathrm{m} ; E-H$, $300 \mu \mathrm{m}$.

specificities for various NPxY-containing transmembrane proteins, including APP (Trommsdorff et al., 1998). Each PI domain protein may also exhibit specificity within the APP family. For example, FE65 binds strongly to APP and APLP2 but not to APLP1 (Bressler et al., 1996; Guenette et al., 1996). Our findings suggest that Dab1 has a binding preference for APLP1.

The NPxY motif is important for internalization of a variety of transmembrane proteins through clathrin-coated pits (Chen et al., 1990). Deletion of NPxY in APP decreases its internalization from the cell surface and reduces its accumulation in lysosomal fractions (Koo and Squazzo, 1994; Ono et al., 1997). Furthermore, chimeric proteins containing the cytosolic domain of APP are rapidly internalized (Lai et al., 1995). Recently, it was demonstrated that binding of $\mathrm{X} 11 \alpha$ to this region increases the halflife of APP in cultured cells (Borg et al., 1998). These interactions could have important biological consequences because endocyto- sis of APP via the clathrin pathway and targeting to endosomes are important for processing of APP and the generation of the amyloid $\beta$ peptide $(\mathrm{A} \beta)$, a major constituent of the amyloid plaques associated with Alzheimer's disease (Haass et al., 1992; Koo and Squazzo, 1994; Selkoe, 1994). Although PI domain proteins have been reported to reduce the turnover of APP, we did not observe any effect of Dab1 on the stability of APLP1 in transfected cells (data not shown).

The most compelling evidence for a functional interaction between Dab1 and APLP1 is the enhanced serine phosphorylation of Dab1 seen in cotransfected mammalian cells (Fig. 5A,B). This result suggests that serine phosphorylation, in addition to tyrosine phosphorylation, may be important in Dab1 signal transduction pathways. We have not yet determined whether the increase in Dab1 phosphorylation is a consequence of a direct interaction between Dab1 and APP family members. Dab1 contains a number of potential sites for serine kinases, such as casein kinase II and protein kinase $\mathrm{C}$, and is phosphorylated by $\mathrm{Cdk} 5$ in vitro (data not shown). The identity of the kinase(s) involved and the biological significance of serine phosphorylation of Dab1 remain to be determined.

Dab1-deficient mice show abnormalities in neuronal migration and positioning of neurons in the brain (Sweet et al., 1996; Howell et al., 1997b; Sheldon et al., 1997; Yoneshima et al., 1997). Our observation that APP family of proteins interact with Dab1, suggests that they may play a role in neuronal migration during brain development. However, targeted disruption of APP, APLP1, and APLP2 genes in mice does not result in altered lamination in the brain (Zheng et al., 1995; Müller et al., 1997). The lack of a major phenotype in these mice may be attributable, in part, to compensation or functional redundancy among closely related APP family members. Importantly, mice in which two of the genes have been disrupted, for example APP and APLP2 or APLP1 and APLP2, die before birth (Müller et al., 1997; von Koch et al., 1997). Thus, it seems that the overlapping function of APP family members is required for normal development.

Several studies have suggested developmental roles for APP family genes. For example, their level of gene expression is regulated during development of the nervous system (Lorent et al., 1995). Also, induction of neuronal differentiation in cultured cells increases expression of all three family members (Konig et al., 1990; Hung et al., 1992; Beckman and Iverfeldt, 1997). Furthermore, both APP and APLP2 are present in elongating axons (Moya et al., 1994; Thinakaran et al., 1995). Other studies have shown that APP is expressed on radial fibers (Trapp and Hauer, 1994), which are present transiently in the developing cortex and provide a substrate for neuronal migration (Rakic, 1972). Thus, there is some circumstantial evidence supporting an interaction between the Reelin-Dab1 pathway and APP family proteins.

Mutations in APP have been linked to autosomal dominant familial Alzheimer's disease, the most common form of late-onset dementia (Price and Sisodia, 1998). Alzheimer's disease is characterized pathologically by the appearance of neuritic plaques containing $\mathrm{A} \beta$ peptide derived from APP and neurofibrillary tangles containing hyperphosphorylated tau protein. Thus far, no direct link has been established between the appearance of amyloid plaques and tau phosphorylation. One of the kinases responsible for the phosphorylation of tau is C dk5 (Imahori and Uchida, 1997), and Cdk5 immunoreactivity increases in neurons that exhibit early-stage neurofibrillary tangles (Pei et al., 1998). It is intriguing that disruption of either $\mathrm{Cdk} 5$ or its activating subunit 
p35 in mice causes a neuronal migration defect similar to that seen in mice lacking Reelin or Dab1 (Ohshima et al., 1996; Chae et al., 1997). These findings, in combination with the data presented here, suggest that Cdk5-p35 and Dab1 may provide a link between APP and tau metabolism in the adult brain.

Numerous functions have been suggested for APP (Selkoe, 1994). It has been implicated in differentiation, attachment, survival, and outgrowth of neurons (Klier et al., 1990; Small et al., 1994; Qiu et al., 1995). Different regions of the extracellular domain of APP have been shown to inhibit proteases and to modulate synaptic activity (Kitaguchi et al., 1988; Oltersdorf et al., 1989; Nalbantoglu et al., 1997; Morimoto et al., 1998). However, the normal function of APP and the consequences of the interaction of Dab1 with APP family proteins in the adult brain are unclear at present. Our results suggest that Dab1 may influence processes involving the APP family of proteins that are important in the developing, as well as the adult, brain.

\section{REFERENCES}

Beckman M, Iverfeldt K (1997) Increased gene expression of betaamyloid precursor protein and its homologues APLP1 and APLP2 in human neuroblastoma cells in response to retinoic acid. Neurosci Lett 221:73-76.

Borg JP, Ooi J, Levy E, Margolis B (1996) The phosphotyrosine interaction domains of X11 and FE65 bind to distinct sites on the YENPTY motif of amyloid precursor protein. Mol Cell Biol 16:6229-6241.

Borg JP, Yang Y, De Taddeo-Borg M, Margolis B, Turner RS (1998) The $\mathrm{X} 11 \alpha$ protein slows cellular amyloid precursor protein processing and reduces $A \beta 40$ and $A \beta 42$ secretion. J Biol Chem 273:14761-14766.

Bork P, Margolis B (1995) A phosphotyrosine interaction domain. Cell 80:693-694.

Bressler SL, Gray MD, Sopher BL, Hu Q, Hearn MG, Pham DG, Dinulos MB, Fukuchi K, Sisodia SS, Miller MA, Disteche CM, Martin GM (1996) cDNA cloning and chromosome mapping of the human Fe65 gene: interaction of the conserved cytoplasmic domains of the human $\beta$-amyloid precursor protein and its homologues with the mouse Fe65 protein. Hum Mol Genet 5:1589-1598.

Chae T, Kwon YT, Bronson R, Dikkes P, Li E, Tsai LH (1997) Mice lacking p35, a neuronal specific activator of Cdk5, display cortical lamination defects, seizures, and adult lethality. Neuron 18:29-42.

Chen WJ, Goldstein JL, Brown MS (1990) NPXY, a sequence often found in cytoplasmic tails, is required for coated pit-mediated internalization of the low density lipoprotein receptor. $\mathrm{J}$ Biol Chem 265:3116-3123.

Chien CT, Wang S, Rothenberg M, Jan LY, Jan YN (1998) Numbassociated kinase interacts with the phosphotyrosine binding domain of Numb and antagonizes the function of Numb in vivo. Mol Cell Biol 18:598-607.

D'Arcangelo G, Curran T (1998) Reeler: new tales on an old mutant mouse. Bioessays 20:235-244.

D’Arcangelo G, Miao GG, Chen SC, Soares HD, Morgan JI, Curran T (1995) A protein related to extracellular matrix proteins deleted in the mouse mutant reeler. Nature 374:719-723.

D’Arcangelo G, Nakajima K, Miyata T, Ogawa M, Mikoshiba K, Curran T (1997) Reelin is a secreted glycoprotein recognized by the CR-50 monoclonal antibody. J Neurosci 17:23-31.

Falconer DS (1951) Two new mutants "trembler" and "reeler," with neurological actions in the house mouse. J Genet 50:192-201.

Goldowitz D, Hamre K (1998) The cells and molecules that make a cerebellum. Trends Neurosci 21:375-382.

Guenette SY, Chen J, Jondro PD, Tanzi RE (1996) Association of a novel human FE65-like protein with the cytoplasmic domain of the $\beta$-amyloid precursor protein. Proc Natl Acad Sci USA 93:10832-10837.

Haass C, Koo EH, Mellon A, Hung AY, Selkoe DJ (1992) Targeting of cell-surface $\beta$-amyloid precursor protein to lysosomes: alternative processing into amyloid-bearing fragments. Nature 357:500-503.

Howell BW, Gertler FB, Cooper JA (1997a) Mouse disabled (mDab1): a Src binding protein implicated in neuronal development. EMBO J 16:121-132.

Howell BW, Hawkes R, Soriano P, Cooper JA (1997b) Neuronal posi- tion in the developing brain is regulated by mouse disabled-1. Nature 389:733-737.

Howell BW, Lanier LM, Frank R, Gertler FB, Cooper JA (1999) The Disabled-1 PTB domain binds to the internalization signals of transmembrane glycoproteins and to phospholipids. Mol Cell Biol 19:5179-5188.

Hung AY, Koo EH, Haass C, Selkoe DJ (1992) Increased expression of $\beta$-amyloid precursor protein during neuronal differentiation is not accompanied by secretory cleavage. Proc Natl Acad Sci USA 89:9439-9443.

Imahori K, Uchida T (1997) Physiology and pathology of tau protein kinases in relation to Alzheimer's disease. J Biochem 121:179-188.

Kaiser C, Michaelis S, Mitchell A (1994) Lithium acetate yeast transformation. In: Methods in yeast genetics: a Cold Spring Harbor Laboratory course manual, pp 133-134. New York: Cold Spring Harbor.

Kang J, Lemaire HG, Unterbeck A, Salbaum JM, Masters CL, Grzeschik KH, Multhaup G, Beyreuther K, Muller-Hill B (1987) The precursor of Alzheimer's disease amyloid A4 protein resembles a cell-surface receptor. Nature 325:733-736.

Kitaguchi N, Takahashi Y, Tokushima Y, Shiojiri S, Ito H (1988) Novel precursor of Alzheimer's disease amyloid protein shows protease inhibitory activity. Nature 331:530-532.

Klier FG, Cole G, Stallcup W, Schubert D (1990) Amyloid $\beta$-protein precursor is associated with extracellular matrix. Brain Res 515:336-342.

Konig G, Masters CL, Beyreuther K (1990) Retinoic acid induced differentiated neuroblastoma cells show increased expression of the $\beta$ A4 amyloid gene of Alzheimer's disease and an altered splicing pattern. FEBS Lett 269:305-310.

Koo EH, Squazzo SL (1994) Evidence that production and release of amyloid beta-protein involves the endocytic pathway. J Biol Chem 269:17386-17389.

Lai A, Sisodia SS, Towbridge IS (1995) Characterization of sorting signals in the $\beta$-amyloid precursor protein cytoplasmic domain. $\mathrm{J}$ Biol Chem 270:3565-3573.

Lorent K, Overbergh L, Moechars D, De Strooper B, Van Leuven F, Van den Berghe H (1995) Expression in mouse embryos and in adult mouse brain of three members of the amyloid precursor protein family, of the $\alpha$-2-macroglobulin receptor/low density lipoprotein receptorrelated protein and of its ligands apolipoprotein E, lipoprotein lipase, $\alpha$-2-macroglobulin and the 40,000 molecular weight receptor-associated protein. Neuroscience 65:1009-1025.

Morimoto T, Ohsawa I, Takamura C, Ishiguro M, Nakamura Y, Kohsaka $S$ (1998) Novel domain-specific actions of amyloid precursor protein on developing synapses. J Neurosci 18:9386-9393.

Moya KL, Benowitz LI, Schneider GE, Allinquant B (1994) The amyloid precursor protein is developmentally regulated and correlated with synaptogenesis. Dev Biol 161:597-603.

Müller U, Gajic V, Hainsellner J, Aguzzi A, Herms J, Tremml P, Wolfer D, Lipp H (1997) Transgenic models to define the physiological role of proteins of the APP-family. Soc Neurosci Abstr 23:1874.

Nalbantoglu J, Tirado-Santiago G, Lahsaini A, Poirier J, Goncalves O, Verge G, Momoli F, Welner SA, Massicotte G, Julien JP, Shapiro ML (1997) Impaired learning and LTP in mice expressing the carboxyl terminus of the Alzheimer amyloid precursor protein. Nature 387:500-505.

Ogawa M, Miyata T, Nakajima K, Yagyu K, Seike M, Ikenaka K, Yamamoto H, Mikoshiba K (1995) The reeler gene-associated antigen on Cajal-Retzius neurons is a crucial molecule for laminar organization of cortical neurons. Neuron 14:899-912.

Ohshima T, Ward JM, Huh CG, Longenecker G, Veeranna, Pant HC, Brady RO, Martin LJ, Kulkarni AB (1996) Targeted disruption of the cyclin-dependent kinase 5 gene results in abnormal corticogenesis, neuronal pathology and perinatal death. Proc Natl Acad Sci USA 93:11173-11178.

Oltersdorf T, Fritz LC, Schenk DB, Lieberburg I, Johnson-Wood KL, Beattie EC, Ward PJ, Blacher RW, Dovey HF, Sinha S (1989) The secreted form of the Alzheimer's amyloid precursor protein with the Kunitz domain is protease nexin-II. Nature 341:144-147.

Ono Y, Kinouchi T, Sorimachi H, Ishiura S, Suzuki K (1997) Deletion of an endosomal/lysosomal targeting signal promotes the secretion of Alzheimer's disease amyloid precursor protein (APP). J Biochem 121:585-590.

Pei JJ, Grundke-Iqbal I, Iqbal K, Bogdanovic N, Winblad B, Cowburn RF (1998) Accumulation of cyclin-dependent kinase $5(\mathrm{cdk} 5)$ in neurons 
with early stages of Alzheimer's disease neurofibrillary degeneration. Brain Res 797:267-277.

Price DL, Sisodia SS (1998) Mutant genes in familial Alzheimer's disease and transgenic models. Annu Rev Neurosci 21:479-505.

Qiu WQ, Ferreira A, Miller C, Koo EH, Selkoe DJ (1995) Cell-surface $\beta$-amyloid precursor protein stimulates neurite outgrowth of hippocampal neurons in an isoform-dependent manner. J Neurosci 15:2157-2167.

Rakic P (1972) Mode of cell migration to the superficial layers of fetal monkey neocortex. J Comp Neurol 145:61-81.

Rice DS, Sheldon M, D'Arcangelo G, Nakajima K, Goldowitz D, Curran T (1998) Disabled-1 acts downstream of reelin in a signaling pathway that controls laminar organization in the mammalian brain. Development 125:3719-3729.

Selkoe DJ (1994) Normal and abnormal biology of the $\beta$-amyloid precursor protein. Annu Rev Neurosci 17:489-517.

Sheldon M, Rice DS, D'Arcangelo G, Yoneshima H, Nakajima K, Mikoshiba K, Howell BW, Cooper JA, Goldowitz D, Curran T (1997) Scrambler and yotari disrupt the disabled gene and produce a reelerlike phenotype in mice. Nature 389:730-733.

Small DH, Nurcombe V, Reed G, Clarris H, Moir R, Beyreuther K, Masters CL (1994) A heparin-binding domain in the amyloid protein precursor of Alzheimer's disease is involved in the regulation of neurite outgrowth. J Neurosci 14:2117-2127.

Sweet HO, Bronson RT, Johnson KR, Cook SA, Davisson MT (1996) Scrambler, a new neurological mutation of the mouse with abnormalities of neuronal migration. Mamm Genome 7:798-802.

Thinakaran G, Kitt CA, Roskams AJ, Slunt HH, Masliah E, von Koch C, Ginsberg SD, Ronnett GV, Reed RR, Price DL (1995) Distribution of an APP homolog, APLP2, in the mouse olfactory system: a potential role for APLP2 in axogenesis. J Neurosci 15:6314-6326.

Trapp BD, Hauer PE (1994) Amyloid precursor protein is enriched in radial glia: implications for neuronal development. J Neurosci Res 37:538-550.

Trommsdorff M, Borg JP, Margolis B, Herz J (1998) Interaction of cytosolic adaptor proteins with neuronal apolipoprotein $\mathrm{E}$ receptors and the amyloid precursor protein. J Biol Chem 273:33556-33560. van der Geer P, Pawson T (1995) The PTB domain: a new protein module implicated in signal transduction. Trends Biochem Sci 20:277-280.

van der Geer P, Wiley S, Gish GD, Lai VK, Stephens R, White MF, Kaplan D, Pawson T (1996) Identification of residues that control specific binding of the Shc phosphotyrosine-binding domain to phosphotyrosine sites. Proc Natl Acad Sci USA 93:963-968.

Vidal M, Brachmann RK, Fattaey A, Harlow E, Boeke JD (1996) Reverse two-hybrid and one-hybrid systems to detect dissociation of protein-protein and DNA-protein interactions. Proc Natl Acad Sci USA 93:10315-10320.

von Koch CS, Zheng H, Chen H, Trumbauer M, Thinakaran G, van der Ploeg LH, Price DL, Sisodia SS (1997) Generation of APLP2 KO mice and early postnatal lethality in APLP2/APP double KO mice. Neurobiol Aging 18:661-669.

Wasco W, Bupp K, Magendantz M, Gusella JF, Tanzi RE, Solomon F (1992) Identification of a mouse brain cDNA that encodes a protein related to the Alzheimer disease-associated amyloid $\beta$ protein precursor. Proc Natl Acad Sci USA 89:10758-10762.

Wasco W, Gurubhagavatula S, Paradis MD, Romano DM, Sisodia SS, Hyman BT, Neve RL, Tanzi RE (1993) Isolation and characterization of APLP2 encoding a homologue of the Alzheimer's associated amyloid $\beta$ protein precursor. Nat Genet 5:95-100.

Yoneshima H, Nagata E, Matsumoto M, Yamada M, Nakajima K, Miyata T, Ogawa M, Mikoshiba K (1997) A novel neurological mutant mouse, yotari, which exhibits reeler-like phenotype but expresses CR-50 antigen/reelin. Neurosci Res 29:217-223.

Zheng H, Jiang M, Trumbauer ME, Sirinathsinghji DJ, Hopkins R, Smith DW, Heavens RP, Dawson GR, Boyce S, Conner MW, et al (1995) $\beta$-Amyloid precursor protein-deficient mice show reactive gliosis and decreased locomotor activity. Cell 81:525-531.

Zhou MM, Ravichandran KS, Olejniczak EF, Petros AM, Meadows RP, Sattler M, Harlan JE, Wade WS, Burakoff SJ, Fesik SW (1995) Structure and ligand recognition of the phosphotyrosine binding domain of Shc. Nature 378:584-592. 